\title{
Azathioprine-induced Myelodysplasia Mimicking Myelodysplastic Syndrome
}

\author{
Masashi Ohe \\ Department of Internal Medicine, JCHO Hokkaido Hospital, Sapporo, Japan
}

An 81-year-old man suffering from autoimmune hepatitis, who had been on prednisolone (10-20 mg/day) and azathioprine (AZA) $(50 \mathrm{mg} /$ day) for about 5 months, was diagnosed with macrocytic anemia during a routine examination. Before treatment with prednisolone and AZA, complete blood count revealed a white blood cell count of $9,780 / \mu \mathrm{L}$, hemoglobin level of $11.7 \mathrm{~g} / \mathrm{dL}$ with a mean corpuscular volume of $91.9 \mathrm{fL}$ (normal range, 80-99 fL), and platelet count of $18.4 \times 10^{4} / \mu \mathrm{L}$. Five months after treatment with prednisolone and AZA, complete blood count revealed a white blood cell count of $6,180 / \mu \mathrm{L}$, hemoglobin level of $7.2 \mathrm{~g} / \mathrm{dL}$ with a mean corpuscular volume of $109.1 \mathrm{fL}$, and platelet count of $17.5 \times 10^{4} / \mu \mathrm{L}$. Serological tests revealed iron level of $116 \mu \mathrm{g} / \mathrm{dL}$ (normal range, 40-190 $\mu \mathrm{g} /$ $\mathrm{dL}$ ), free thyroxine level of $1.10 \mathrm{ng} / \mathrm{dL}$ (normal range, 0.9-1.70 $\mathrm{ng} / \mathrm{dL}$ ), vitamin B12 level of $462 \mathrm{pg} / \mathrm{mL}$ (normal range, 233-914 pg/mL), folic acid level of $7.4 \mathrm{ng} / \mathrm{mL}$ (normal range, $3.6-12.9 \mathrm{ng} / \mathrm{mL}$ ), and anti-DNA antibody (Ab) level of $\langle 1.7$ $\mathrm{IU} / \mathrm{mL}$ (normal value, $\langle 6.0 \mathrm{IU} / \mathrm{mL}$ ). The results of tests for antivirus immunoglobulin $\mathrm{M}$ (IgM) Ab were negative for antiparvovirus B19 IgM Ab, anti-Epstein-Barr virus capsid antigen $\mathrm{IgM} \mathrm{Ab}$, and anti-cytomegalovirus IgM Ab. Bone marrow aspiration revealed a normocellular bone marrow. The aspiration smear revealed a neutrophil with hypersegmentation (Fig. 1), an erythroblast with a bilobulated nucleus (Fig. 2A), an erythroblast with abundant cytoplasm and a multilobulated nucleus (Fig.
2B), an erythroblast with a multilobulated nucleus and HowellJolly bodies (Fig. 2C), an erythrocyte with abundant cytoplasm and Howell-Jolly bodies (Fig. 2D), and a megakaryocyte with separated nuclei (Fig. 3). However, no chromosomal aberrations were observed. Based on these findings, vitamin B12 or folic acid deficiency, viral infections, and systemic lupus erythematosus that led to anemia with myelodysplasia were not diagnosed. Considering AZA-induced hematopoietic disorder, AZA treatment was discontinued, leading to normalization of macrocytic

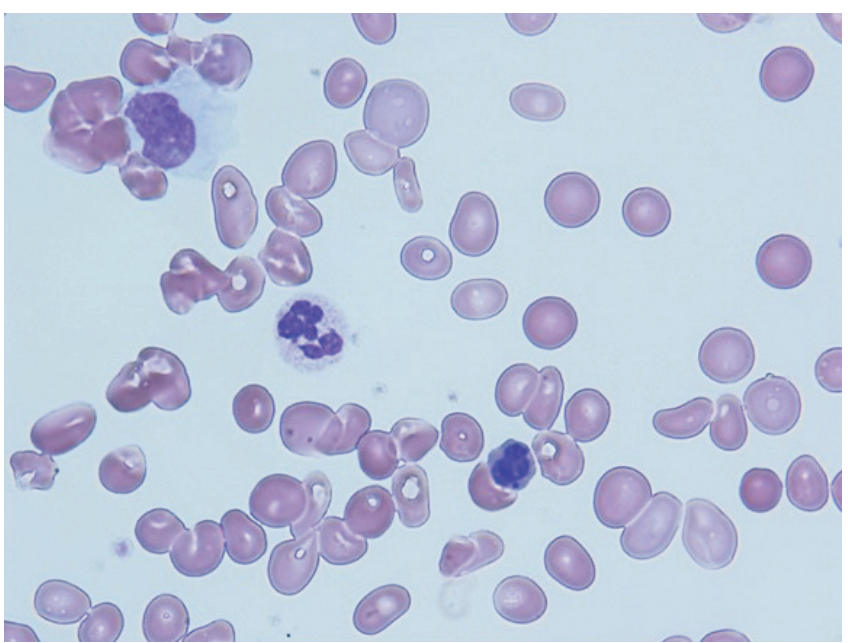

Fig. 1. The bone marrow aspiration smear reveals a neutrophil with hypersegmentation (Wright-Giemsa stain, $\times 1,000$ ).

Received December 10, 2018, Revised March 29, 2019, Accepted May 13, 2019

Corresponding author Masashi Ohe, Department of Internal Medicine, JCHO Hokkaido Hospital, 1-8-3-18 Nakanoshima, Toyohira-ku, Sapporo 062-8618, Japan Tel: 81-11-831-5151, Fax: 81-11-821-3851,E-mail: masshi@isis.ocn.ne.jp

This is an Open Access article distributed under the terms of the Creative Commons Attribution Non-Commercial License (http://creativecommons.org/licenses/by-nc/4.0) which permits unrestricted non-commercial use, distribution, and reproduction in any medium, provided the original work is properly cited. 

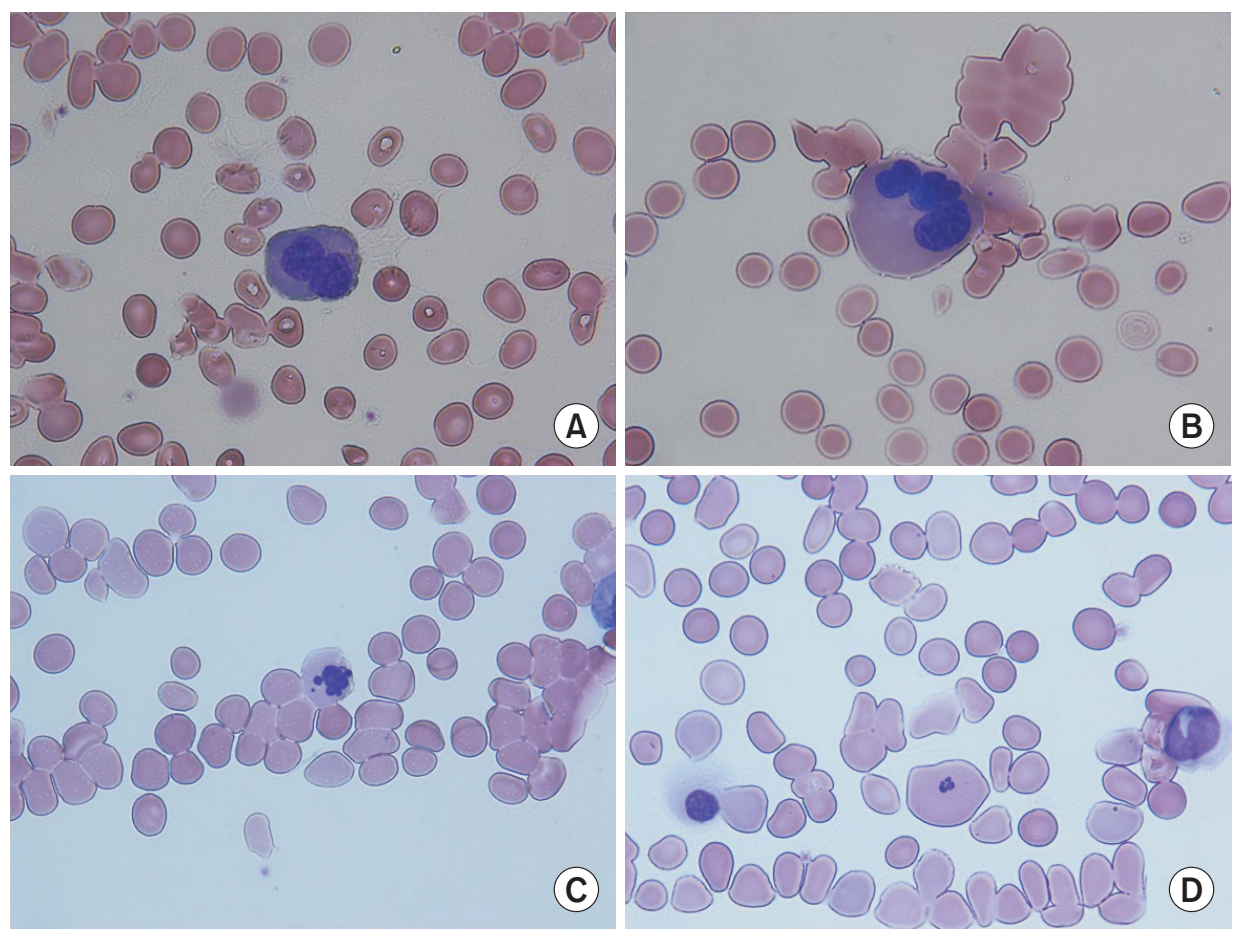

(c)

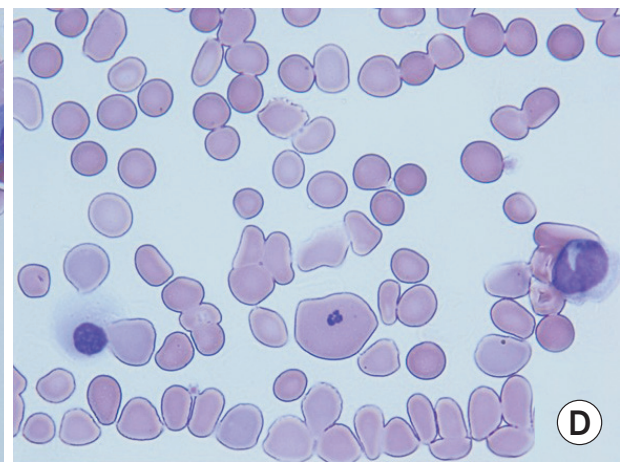

Fig. 2. (A) The bone marrow aspiration smear reveals an erythroblast with a bilobulated nucleus. (B) The bone marrow aspiration smear reveals an erythroblast with abundant cytoplasm and a multilobulated nucleus. (C) The bone marrow aspiration smear reveals an erythroblast with a multilobulated nucleus and Howell-Jolly bodies. (D) The bone marrow aspiration smear reveals an erythrocyte with abundant cytoplasm and HowellJolly bodies. (A-D) Wright-Giemsa stain, $\times 1,000$.

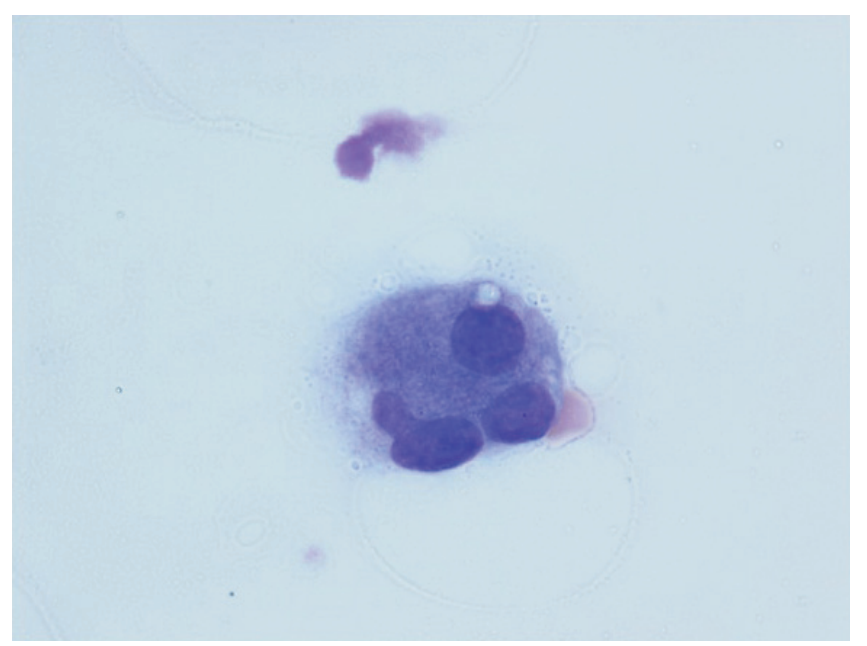

Fig. 3. The bone marrow aspiration smear reveals a megakaryocyte with separated nuclei (Wright-Giemsa stain, ×1,000).

anemia over a 4-month period. Therefore, it appeared that AZA cessation alleviated the patient's macrocytic anemia.

AZA, a recognized carcinogen, is widely used in patients with autoimmune diseases and is associated with the development of therapy-related myelodysplastic syndrome (MDS) and acute myeloid leukemia. It has been reported that AZA had been administered for 6 to 192 months (median, 65 months) to a cumulative dose of 19 to $750 \mathrm{~g}$ (median, $146 \mathrm{~g}$ ), before therapy-related MDS and acute myeloid leukemia developed [1]. Moreover, MDS following treatment with AZA is associated with aberrations of chromosome 7 [2,3]. In the present case, AZA had been administered for only 5 months to a cumulative dose of $7.6 \mathrm{~g}$. At the same time, no chromosomal aberrations were observed during this period. Based on these findings, the patient was finally diagnosed with AZA-induced myelodysplasia, not AZA-related MDS. Although bone marrow aspiration was not carried out again, this myelodysplasia was thought to be transient.

Thus, clinicians should take notice of AZA-induced myelodysplasia mimicking MDS because it can be safely treated with drug withdrawal.

\section{References}

1. Kwong YL. Azathioprine: association with therapy-related myelodysplastic syndrome and acute myeloid leukemia.J Rheumatol 2010;37:485-490.

2. Knipp S, Hildebrandt B, Richter J, Haas R, Germing U, Gattermann N. Secondary myelodysplastic syndromes following treatment with azathioprine are associated with aberrations of chromosome 7. Haematologica 2005;90:691-693.

3. Ahmad OF, Keane MG, McCartney S, Khwaja A, Bloom SL. Azathioprine-associated myelodysplastic syndrome in two patients with ulcerative colitis. Frontline Gastroenterol 2013;4:205-209. 